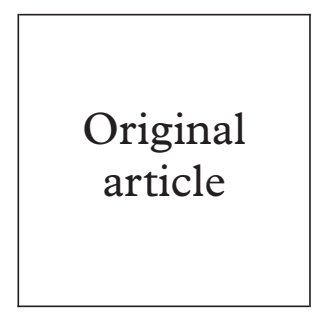

Original article

Sexually Transmitted Infections Research Centre, Marion Villa, Westmead Hospital, Sydney, NSW 2145, Australia

C Marks

R L Tideman

C S Estcourt

A Mindel

Department of Public Health and

Community Medicine, University of Sydney

G Berry

Correspondence to:

A Mindel

adrianm@icpmr.wsahs.nsw. gov.au

Accepted for publication 18 July 2000

website

extra

Further data on variables associated with presumptive PID are available as a table on the STI website.

www.sextransinf.com

\title{
Assessment of risk for pelvic inflammatory disease in an urban sexual health population
}

\author{
C Marks, R L Tideman, C S Estcourt, G Berry, A Mindel
}

Objectives: To determine the sexual and demographic risk factors for the acquisition of presumptive pelvic inflammatory disease (PID).

Methods: A retrospective, case-control study in women, who attended the Sydney Sexual Health Centre (SSHC), between April 1991 and December 1997. Logistic regression analysis was used to adjust for confounding variables.

Results: 741 women with PID and an equal number of controls were included. Cases were significantly younger than controls $(\mathrm{p}<0.001) .42 \%$ of cases were born in north or South East Asia, compared with $12 \%$ of the controls $(\mathrm{p}<0.001)$. The adjusted odds ratio for being born in north or South East Asia was 2.8 (95\% CI 1.70-4.46), for not speaking English at home was 1.6 (95\% CI 1.02-2.55), for having had previous PID was 5.9 (95\% CI 3.59-9.73), and for being employed in the commercial sex industry and being born in north or South East Asia was 2.8 (95\% CI 1.22-6.22). Women aged 15-19 were at considerable risk of developing PID (OR 5.3 (95\% CI 2.76-10.11)). Women with previous human papillomavirus infection were significantly less likely to develop PID (OR 0.6 (95\% CI 0.42-0.79)). The use of IUCDs (OR 4.5 (95\% CI 2.14-9.39)), condoms (OR 1.4 (95\% CI 1.03-1.87)), and not using contraception (OR 1.8 (95\% CI 1.20-2.76)) was each associated with an increased risk.

Conclusions: Several measures may help to reduce the burden of PID. Women should be encouraged to delay the onset of sexual activity and IUCDs should not be used in young women. Sexual health services for women whose home language is not English, and for commercial sex workers born in north or South East Asia should be improved.

(Sex Transm Inf 2000;76:470-473)

Keywords: pelvic inflammatory disease; risk factors; risk markers

\section{Introduction}

Pelvic inflammatory disease (PID) is the clinical syndrome resulting from ascending infection from the lower genital tract to involve the endometrium, Fallopian tubes and/or adjacent pelvic structures. ${ }^{1}$ Consequences of infection include tubal infertility, ectopic pregnancy, and chronic pelvic pain. ${ }^{2}$ The severity of the sequelae in conjunction with the relatively high incidence of PID in some communities invoke costly consequences at the level of personal and public health. ${ }^{3-5}$

Diagnosis of PID is often difficult. The "gold standard" for diagnosis relies on the laparoscopic appearance of Fallopian tube inflammation $^{6}$ but cost and limited availability of the technique often preclude its use. In the absence of laparoscopy, the triad of lower abdominal pain, cervical motion tenderness, and bilateral adnexal tenderness has been advocated as the minimal criterion for clinical diagnosis of PID. ${ }^{7}$ However, many cases of PID are asymptomatic or present with minimal or atypical symptoms. ${ }^{1}$ This means that diagnosing PID on purely clinical grounds is often difficult and the margin for error is wide. ${ }^{8}$ In this context, knowledge of risk factors and markers for PID could substantially aid diagnosis. Although multiple organisms have been implicated in the pathogenesis of PID, ${ }^{910}$ chlamydial and gonococcal infections account for the majority of infections. ${ }^{1}$ Thus, risk assessment in individual patients has relied on estimation of the likelihood of exposure to a sexually transmitted infection (STI). ${ }^{11}$

Previous studies have linked a wide range of interrelated risk factors (direct causal association)/or markers (indirect relation) to the acquisition of PID. In general, presence of an STI and the use of intrauterine contraceptive devices (IUCDs) have been consistently reported as risk factors, whereas previous PID, previous gonorrhoea, young age, and multiple sexual partners have been reported as risk markers. ${ }^{11-15}$

The objectives of this study were to identify sexual, social, and demographic risk factors for the acquisition of PID diagnosed presumptively in women attending a sexual health service and on the basis of these findings to formulate health promotion recommendations to reduce the incidence and consequences of PID.

\section{Subjects and methods}

Cases were all women who attended the Sydney Sexual Health Centre (SSHC), a public sexual health service in the central business district of the city between 1 April 1991 and 31 December 1997, who were newly diagnosed as having "presumptive" PID by clinic medical personnel. Cases were derived from the clinic database on the basis of a diagnosis of presumptive PID. Controls were women who attended the clinic over the same period who were not diagnosed as having PID. Controls were matched with cases in a one to one ratio 
Table 1 Social history comparing cases and controls

\begin{tabular}{|c|c|c|c|}
\hline Variable & Cases (\%) & Controls (\%) & $p$ Value \\
\hline \multicolumn{4}{|l|}{ Age $(n=1481)$} \\
\hline $15-19$ & $65 / 740(8.8 \%)$ & $14 / 741(1.9 \%)$ & \\
\hline $20-24$ & $246 / 740(33.2 \%)$ & $140 / 741(18.9 \%)$ & \\
\hline $25-29$ & $229 / 740(30.9 \%)$ & $210 / 741(28.3 \%)$ & \\
\hline $30-34$ & $119 / 740(16.1 \%)$ & $162 / 741(21.9 \%)$ & $<0.001^{\star}$ \\
\hline $35-39$ & $46 / 740(6.2 \%)$ & $109 / 741(14.7 \%)$ & \\
\hline$>39$ & $35 / 740(4.7 \%)$ & $106 / 741(14.3 \%)$ & \\
\hline \multicolumn{4}{|l|}{ Country of birth $(n=1445)$} \\
\hline Australia and NZ & $307 / 727(42.2 \%)$ & $475 / 718(66.2 \%)$ & \\
\hline Polynesia and Melanesia & $10 / 727(1.4 \%)$ & $7 / 718(1.0 \%)$ & \\
\hline Europe and UK & $70 / 727(9.6 \%)$ & $114 / 718(15.9 \%)$ & \\
\hline $\mathrm{N}$ and SE Asia & $304 / 727(41.8 \%)$ & $84 / 718(11.7 \%)$ & \\
\hline Central Asia & $2 / 727(0.3 \%)$ & $4 / 718(0.6 \%)$ & $<0.001^{\star}$ \\
\hline Middle East & $3 / 727(0.4 \%)$ & $4 / 718(0.6 \%)$ & \\
\hline S America & $17 / 727(2.3 \%)$ & $10 / 718(1.4 \%)$ & \\
\hline N America & $6 / 727(0.8 \%)$ & $15 / 718(2.1 \%)$ & \\
\hline Africa & $8 / 727(1.1 \%)$ & $5 / 718(0.7 \%)$ & \\
\hline English spoken at home $(n=1453)$ & $435 / 725(60.0 \%)$ & $644 / 728(88.5 \%)$ & $<0.001^{\star \star}$ \\
\hline Cigarette smoker $(n=1458)$ & $338 / 735(46.0 \%)$ & $262 / 723(36.2 \%)$ & $<0.001^{\star \star}$ \\
\hline $\begin{array}{l}\text { Alcohol consumption }>140 \mathrm{~g} / \text { week } \\
\quad(\mathrm{n}=1456)\end{array}$ & $46 / 735(6.3 \%)$ & $50 / 721(6.9 \%)$ & $0.673^{\star \star}$ \\
\hline \multicolumn{4}{|l|}{$\begin{array}{l}{ }^{\star} \text { Pearson } \chi^{2} \text { test. } \\
{ }_{\star \star} \text { Fisher's exact test. }\end{array}$} \\
\hline \multicolumn{4}{|c|}{ Table 2 Obstetric history comparing cases and controls } \\
\hline Variable & Cases $(\%)$ & Controls (\%) & p Value \\
\hline \multicolumn{4}{|l|}{ Contraception currently used $(n=1372)$} \\
\hline Hormonal & $255 / 693(36.8 \%)$ & $220 / 679(32.4 \%)$ & \\
\hline IUCD $†$ & $26 / 693(3.8 \%)$ & $18 / 679(2.7 \%)$ & \\
\hline Diaphragm/cap & $4 / 693(0.6 \%)$ & $20 / 679(2.9 \%)$ & \\
\hline Condoms & $215 / 693(31.0 \%)$ & $210 / 679(30.9 \%)$ & $<0.001^{\star}$ \\
\hline Hormonal and barrier & $63 / 693(9.1 \%)$ & $46 / 679(6.8 \%)$ & \\
\hline Nil & $95 / 693(13.7 \%)$ & $92 / 679(13.5 \%)$ & \\
\hline Not needed $\ddagger$ & $35 / 693(5.1 \%)$ & $73 / 679(10.8 \%)$ & \\
\hline Been pregnant $(n=1271)$ & $396 / 665(59.5 \%)$ & $315 / 606(52.0 \%)$ & $0.008^{\star \star}$ \\
\hline Had a termination of pregnancy $(n=1084)$ & $308 / 579(53.2 \%)$ & $235 / 505(46.5 \%)$ & $0.033^{\star \star}$ \\
\hline Had a miscarriage $(n=1072)$ & $175 / 575(30.4 \%)$ & $126 / 497(25.3 \%)$ & $0.066^{\star \star}$ \\
\hline Had a live birth $(n=1073)$ & $243 / 578(42.0 \%)$ & $155 / 495(31.3 \%)$ & $<0.001^{\star \star}$ \\
\hline
\end{tabular}

by day of attendance-usually the next registered patient. Controls also were derived from the clinic database.

Data were recorded at the time of presentation using a standardised medical record form and then entered onto the clinic database. Analysis was performed retrospectively. Variables analysed in the study included age; country of birth; whether English was spoken at home; whether they currently were in a sexual relationship; condom use with non-paying partners; lifetime number of opposite sex partners; whether they had ever had sex with a homosexual or bisexual male, an injecting drug user, a male with multiple previous sexual partners, or a person from outside Australia; contraception; pregnancy history; previous termination(s) of pregnancy or miscarriage; cigarette smoking; alcohol consumption; and history of previous gonorrhoea, syphilis, chlamydia, PID, genital herpes, genital warts, bacterial vaginosis, candidiasis, trichomoniasis, and urinary tract infections. The history of STIs included all infections diagnosed up to and including the day of diagnosis. Continuous variables, such as age were treated as categorical variables by grouping. Comparisons were made using $\chi^{2}$ tests for categorical variables, Student's $t$ test, and Fisher's exact test as appropriate. Crude odds ratios (OR) with their 95\% confidence interval (CI) were calculated using univariate analysis. Factors which were related to a diagnosis of PID on univariate analysis $(p<0.10)$ and factors considered possibly to be of clinical importance were further analysed using unconditional logistic regression models to permit statistical control of confounding variables. Variables with more than $10 \%$ missing data were considered unreliable and excluded from the multivariate analysis. Analysis was performed using the SPSS ${ }^{16}$ and SAS $^{17}$ statistical packages.

The study was approved by South Eastern Sydney Area Health Service research ethics committee.

\section{Results}

Seven hundred and forty one patients with presumptive PID were identified together with an equal number of controls. Table 1 shows the social history comparing patients and controls. Patients with PID were significantly younger than controls with $73 \%$ under 30 years of age compared with $49 \%$ of the controls $(p<0.001)$. There were marked differences comparing country of birth in the two groups with two thirds of controls being born in Australia or New Zealand compared with $42 \%$ of cases. An additional $42 \%$ of cases were born in north or South East Asia, compared with $12 \%$ of the controls $(p<0.001)$. Finally, cases were more likely to smoke than controls $(46 \%$ v 36\%, $\mathrm{p}<0.001)$.

Table 2 shows the obstetric and contraception history in these two groups. Cases were more likely to have had termination of pregnancy, a live birth, or to have ever been pregnant than the controls. Differences in contraceptive use were small but statistically different $(\mathrm{p}<0.001)$.

Sexual history and history of previous STIs is shown in table 3. A history of sex work, having a partner from overseas, and inconsistent condom use were all significantly more common in cases than controls. Past gonorrhoea and PID both occurred more often in cases than controls. However, genital herpes, genital warts, bacterial vaginosis, candidiasis, and trichomoniasis all occurred more often in controls than in cases.

On multivariate analysis several factors were found to be associated with presumptive PID. The adjusted odds ratio for being born in north or South East Asia was 2.8 (95\% CI 1.704.46) and for not speaking English at home was 1.6 (95\% CI 1.02-2.55). Having a history of previous PID carried a very high risk for the development of subsequent PID (OR 5.9 (95\% CI 3.59-9.73)) and women employed in the commercial sex industry who were born in north or South East Asia were more than twice as likely to develop PID than those who were not.

Women below the age of 25 were at considerable risk of developing PID (for those aged 15-19 the OR was 5.3 (95\% CI 2.76-10.11)). However, those above 30 were less likely to develop PID (for those aged 39 or more the OR was 0.3 (95\% CI $0.16-0.45))$. Women with previous HPV infection were significantly less 
Table 3 Sexual history comparing cases and controls

\begin{tabular}{|c|c|c|c|}
\hline Variable & Cases & Controls & p value \\
\hline Currently in sexual relationship $(\mathrm{n}=770)$ & $210 / 374(56.1 \%)$ & $220 / 396(55.6 \%)$ & $0.885^{\star \star}$ \\
\hline \multicolumn{4}{|c|}{ Condom use for vaginal/anal sex with non-paying partner(s) in past 3 months $(n=847)$} \\
\hline None & $137 / 488(28.1 \%)$ & $59 / 359(16.4 \%)$ & \multirow{5}{*}{$<0.001^{\star}$} \\
\hline Sometimes $(<50 \%)$ & $70 / 488(14.3 \%)$ & $28 / 359(7.8 \%)$ & \\
\hline Usually (>50\%) & $104 / 488(21.3 \%)$ & $41 / 359(11.4 \%)$ & \\
\hline Always $(100 \%)$ & $138 / 488(28.3 \%)$ & $209 / 359(58.2 \%)$ & \\
\hline Not applicablet & $39 / 488(8.0 \%)$ & $22 / 359(6.1 \%)$ & \\
\hline \multicolumn{4}{|l|}{ Number of non-paying opposite sex partner(s) in life time $(n=1461)$} \\
\hline 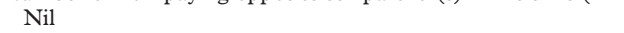 & $96 / 736(13.0 \%)$ & $95 / 725(13.1 \%)$ & \multirow{4}{*}{$<0.001^{\star}$} \\
\hline One & $79 / 736(10.7 \%)$ & $28 / 725(3.9 \%)$ & \\
\hline Two & $69 / 736(9.4 \%)$ & $39 / 725(5.4 \%)$ & \\
\hline Three or more & $492 / 736(66.8 \%)$ & $563 / 725(77.7 \%)$ & \\
\hline Commercial sex worker (ever) $(n=1482)$ & $211 / 741(28.5 \%)$ & $58 / 741(7.8 \%)$ & $<0.001^{\star \star}$ \\
\hline \multicolumn{4}{|l|}{ Ever had sex with: } \\
\hline A homo/bisexual male $(n=1019)$ & $34 / 615(5.5 \%)$ & $30 / 404(7.4 \%)$ & $0.236^{\star \star}$ \\
\hline An IDU $(n=1037)$ & $52 / 615(8.5 \%)$ & $49 / 422(11.6 \%)$ & $0.109^{\star \star}$ \\
\hline A heterosexual male with multiple other partners $(n=1086)$ & $199 / 638(31.2 \%)$ & $137 / 448(30.6 \%)$ & $0.842^{\star \star}$ \\
\hline A male from outside Australia $(n=1450)$ & $262 / 735(35.6 \%)$ & $117 / 715(16.4 \%)$ & $<0.001^{\star \star}$ \\
\hline \multicolumn{4}{|l|}{ Patient reported history of $(n=1482)$} \\
\hline Gonorrhoea & $84 / 741(11.3 \%)$ & $54 / 741(7.3 \%)$ & 0.009 \\
\hline Syphilis & $16 / 741(2.2 \%)$ & $7 / 741(0.9 \%)$ & 0.910 \\
\hline Chlamydia & $129 / 741(17.4 \%)$ & $121 / 741(16.3 \%)$ & 0.627 \\
\hline PID & $97 / 741(13.1 \%)$ & $27 / 741(3.6 \%)$ & $<0.001$ \\
\hline Genital herpes & $94 / 741(12.7 \%)$ & $175 / 741(23.6 \%)$ & $<0.001$ \\
\hline Genital warts & $44 / 741(5.9 \%)$ & $73 / 741(9.9 \%)$ & 0.007 \\
\hline Bacterial vaginosis & $176 / 741(23.8 \%)$ & $226 / 741(30.5 \%)$ & 0.004 \\
\hline Candidiasis & $15 / 741(2.0 \%)$ & $29 / 741(3.9 \%)$ & 0.045 \\
\hline Trichomoniasis & $81 / 741(10.9 \%)$ & $55 / 741(7.4 \%)$ & 0.024 \\
\hline Urinary tract infection & & & \\
\hline
\end{tabular}

†No penetrative vaginal or anal sexual intercourse.

¥Injecting drug user.

$\star$ Pearson's $\chi^{2}$ test.

$\star \star$ Fisher's exact test.

likely to develop PID than those without (OR 0.6 (95\% CI 0.42-0.79)).

Contraceptive history revealed that the use of IUCD, using condoms, and not using contraception were each associated with an increased risk. However, IUCD users carried the greatest risk (OR 4.5 (95\% CI 2.14-9.39)).

\section{Discussion}

This case-control study has shown that several factors including country of birth (north and South East Asia), language other than English spoken at home, young age, previous PID, being involved in the commercial sex industry, use of the IUCD, condoms or failure to use contraception were all independently associated with presumptive PID. Women who were older than 30 years and had a history of HPV infection were less likely to be diagnosed with presumptive PID.

The strengths of this study include the large number of cases and the diversity of available information. However, the study has a number of weaknesses including retrospective analysis of data and missing data. Some variables had a considerable proportion of observations missing - this rendered several variables unreliable and those with more than $10 \%$ missing were excluded from the multivariate analysis. Secondly, the generalisability of data derived from an inner city sexual health clinic may be limited. Finally, as cases were diagnosed only presumptively, it is possible that PID was overdiagnosed, particularly in sex workers who may be perceived as being a high risk for the development of PID.

None the less, this study has produced some useful information which will be helpful to direct health promotion activities. The importance of young age, a history of previous PID, and the use of IUCDs confirm the findings from previous studies. ${ }^{14}{ }^{15}$ Additional factors identified in this study include being born in north or South East Asia, being a commercial sex worker who was born in north or South East Asia, and not speaking English at home. The association with country of birth may reflect different patterns of health care and health seeking behaviour in parts of Asia. The relation of PID with not speaking English at home may be explained on the basis of poorer access to health care for Australians from nonEnglish speaking backgrounds as well as cultural differences in relation to sexual matters. Sex workers are often considered to be at increased risk of acquiring STIs, particularly in the developing world ${ }^{18-20}$ and, our study identified the interaction of sex work and country of birth as a risk factor for presumptive PID, perhaps as mentioned above, reflecting the greater possibility of diagnosing PID in this group of women.

On univariate analysis a history of previous gonorrhoea and previous PID were significantly more common in cases than controls and previous PID remained as an independent variable. Other previous STIs and genital tract infections including genital herpes, genital warts, bacterial vaginosis, candidiasis, and trichomoniasis were less common in cases than controls. On multivariate analysis, genital warts remained as an independent variable (OR 0.6, $\mathrm{p}=0.0007)$. The reason why individuals with genital warts are less likely to develop PID is unclear. One possible explanation is that women with previous genital warts who usually attend the clinic on several occasions may be more aware of sexual health and safer sex issues.

The apparent link between condom use and presumptive PID (OR 1.4) is intriguing but probably misleading. Condom use was as- 
sessed in two ways, firstly, as a general question on contraception and, secondly, directly in relation to non-paying partners (see table 3). The former showed that condom use for contraception in the two groups was similar. However, the latter showed that $28.1 \%$ of cases and $16.4 \%$ of controls never used condoms and $28.3 \%$ of cases and $59.5 \%$ of controls always used condoms $(p<0.001)$. The reliability of these data is questionable as data were missing from over $40 \%$ of cases and controls. In addition, condom use with sex clients was not assessed.

On the basis of this study it is possible to establish guidelines that will help to reduce the burden of PID. Firstly, in young women, IUCDs should only be considered in exceptional circumstances. Secondly, women should be encouraged to delay the onset of sexual activity. Finally, health services for women whose home language is not English, and for commercial sex workers born in north or South East Asia, may require specific targeting to improve sexual health screening and advice.

We would like to thank Katherine Wagner for her help in retrieving notes, Dr Susanna Smart and Jude Page for recording data, Richard Rohrsheim for retrieving information from the SSHC database, and Professor Anne Johnson for advice and encouragement.

Contributors: CM, database management and statistical analysis; RT, study coordination, data analysis and interpretation, and report writing; $\mathrm{CE}$, interpretation of data and report writing; report writing; CE, interpretation of data and report writing;
GB, statistical advice and assistance with study design, data GB, statistical advice and assistance with study design, data analysis and interpretation, and manuscript review; AM,

1 Weström L, Eschenbach D. Pelvic inflammatory disease. In: Holmes KK, Sparling PF, Mårdh $\mathrm{P}$, et al, eds. Sexually transmitted diseases. 3rd ed. New York: McGraw-Hill 1999:783-809.

2 Weström L, Joesoef R, Reynolds G, et al. Pelvic inflammatory disease and infertility. A cohort study of 1,844 women with laparoscopically verified disease and 657 control women with normal laparoscopic results. Sex Transm Di 1992;19:185-92.
3 Aral SO, Mosher WD, Cates W Jr. Self-reported pelvic inflammatory disease in the United States, 1988. fAMA 1991;266:2570-3

4 Expert Committee on Pelvic Inflammatory Disease. Pelvic inflammatory disease: research directions in the 1990s. Sex Transm Dis 1991;18:46.

5 Kani J, Adler MW. Epidemiology of pelvic inflammatory disease. In: Berger GS, Weström L, eds. Pelvic inflammatory disease. New York: Raven Press, 1992:7.

6 Jacobson L, Weström L. Objectivized diagnosis of acute pelvic inflammatory disease. Diagnostic and prognostic value of routine laparoscopy. Am f Obstet Gynecol 1969;105: 1088-98.

7 Centres for Disease Control and Prevention. MMWR guidelines for treatment of sexually transmitted diseases. Atlanta, GA: CDC 1998;47:79-86.

8 Mann SN, Smith JR, Barton SE. Pelvic inflammatory disease. Int $\mathcal{F}$ STD AIDS 1996;7:315-21.

9 Eschenbach DA, Buchanan TM, Pollock HM, et al. Polymicrobial etiology of acute pelvic inflammatory disease. N Engl f Med 1975;293:166-71.

10 Hemsell DL, Nobles BJ, Heard MC, et al. Upper and lower reproductive tract bacteria in 126 women with acute pelvic inflammatory disease. Microbial susceptibility and clinical response to four therapeutic regimes. I Reprod Med 1988;33 799-805.

11 Washington AE, Aral SO, Wolner-Hanssen P, et al. Assessing risk for pelvic inflammatory disease and its sequelae. 7AMA 1991;266:2581-6.

12 Weström L. Incidence, prevalence and trends of pelvic inflammatory disease and its consequences in indistrialized countries. Am f Obstet Gynecol 1980;138:880-92.

13 Sweet RL. Sexually transmitted diseases. Pelvic inflammatory disease and infertility in women. Infect Dis Clin N Am 1987;1:199-215.

14 Farley TM, Rosenberg MJ, Rowe PJ, et al. Intrauterine devices and pelvic inflammatory disease: an international perspective. Lancet 1992;339:785-8.

15 Jossens MO, Eskenazi B, Schachter J, et al. Risk factors for pelvic inflammatory disease. A case control study. Sex Transm Dis 1996;23:239-47.

16 SPSS: Statistical package for the social sciences [computer program], version 7.0. Chicago, IL: SPSS Inc, 1995.

17 SAS System Windows Version 6.12 [computer program]. SAS Institute Inc, Cary, NC, USA, 1989-96.

18 D'Costa LJ, Plummer FA, Bowmer I, et al. Prostitutes are a major reservoir of sexually transmitted disease in Nairobi, Kenya. Sex Transm Dis 1985;12:64-7.

19 Venegas VS, Madrid JP, Lorenzana I, et al. Human immunodeficiency virus infection and syphilis in Honduran female prostitutes. Intl f STD AIDS 1991;2:110-3.

20 Bonhomme MG, Rojanapithayakorn W, Feldblum PJ, et al. Incidence of sexually transmitted diseases among massage parlour employees in Bangkok. Int f STD AIDS 1994;5: $214-7$. 